УДК 633.174:631.582.3(470.44/.47)

ЭФФЕКТИВНОСТЬ ВКЛЮЧЕНИЯ КУКУРУЗЫ И ЗЕРНОВОГО СОРГО

В СЕВООБОРОТЫ С КОРОТКОЙ РОТАЦИЕЙ

В ЗАСУШЛИВЫХ УСЛОВИЯХ НИЖНЕГО ПОВОЛЖЬЯ

\author{
Плаксина В.С., Асташов А.Н., Бочкарева Ю.В., Пронудин К.А., \\ Сучкова М.Г., Ефремова И.Г.
}

ФГБНУ Российский научно-исследовательский и проектно-технологический институт сорго и кукурузы «Россорго», Саратов, e-mail: rossorgo@yandex.ru

\begin{abstract}
В повышении эффективности и устойчивости земледелия решающее значение имеют научно обоснованное размещение культур, применение рациональной структуры посевных площадей и освоение экономически обоснованных севооборотов. Целью наших исследований было выявить эффективность включения кукурузы и зернового сорго в севообороты с короткой ротацией в условиях Нижнего Поволжья. В статье дается оценка урожайности зерна сельскохозяйственных культур и продуктивности трехпольных экспериментальных севооборотов, заложенных на опытном поле ФГБНУ РосНИИСК «Россорго». Исследования проводились в различные по погодным условиям годы, что позволило всесторонне оценить продуктивность изучаемых культур и севооборотов. В ходе исследований выявлено, что в трехпольных севооборотах максимальная урожайность получена у озимой пшеницы $(2,62$ т/га), кукурузы $(3,89$ т/га) и зернового сорго (2,53 т/га). Сравнительный анализ позволил сформулировать заключение, что эти культуры обеспечивают наибольший выход зерна в севооборотах. Выход зерна с гектара пашни составил 2,17 т и 1,71 т соответственно при средней продуктивности всех изучаемых севооборотов 1,60 т. При формировании структуры посевов для засушливых регионов необходимо включение культур разных хозяйственно-биологических типов: озимых, ранних и поздних яровых. Включение засухоустойчивых поздних культур, способных восполнять потери урожая других культур, обеспечивает стабилизацию выхода продукции. Необходимым условием для обеспечения стабильности продуктивности в связи с низким значением гидротермического коэффициента в засушливых условиях является включение звена пар - озимая пшеница. Также целесообразно включать в структуру посевных площадей кукурузу и зерновое сорго, так как эти культуры обеспечивают наибольший выход зерна в севооборотах.
\end{abstract}

Ключевые слова: продуктивность, урожайность, севооборот, гидротермический коэффициент, кукуруза, сорго

\title{
EFFICIENCY OF INCLUDING MAIZE AND GRAIN SORGHUM IN CROP ROTATIONS WITH SHORT ROTATION IN ARID CONDITIONS OF THE LOWER VOLGA REGION
}

\author{
Plaksina V.S., Astashov A.N., Bochkareva Y.V., Pronudin K.A., \\ Suchkova M.G., Efremova I.G. \\ Russian research and design and technological Institute of sorghum and corn "Rossorgo», \\ Saratov,e-mail: rossorgo@yandex.ru
}

\begin{abstract}
Science-based crop placement, the use of a rational structure of acreage, and the development of economically sound crop rotations are crucial for improving the efficiency and sustainability of agriculture. The purpose of our research was to identify the effectiveness of including corn and grain sorghum in crop rotations with short rotation in the Lower Volga region. The article provides an assessment of the grain yield of agricultural crops and the productivity of three-field experimental crop rotations laid on the experimental field of «Rossorgo». The studies were conducted in different weather conditions in the years that allowed a comprehensive assessment of the productivity of the studied crops and crop rotations. The research revealed that in three-field crop rotations, the maximum yield was obtained in winter wheat $(2,62 \mathrm{t} / \mathrm{ha})$, corn $(3,89 \mathrm{t} / \mathrm{ha})$ and grain sorghum $(2,53 \mathrm{t} / \mathrm{ha})$. Comparative analysis allowed us to conclude that these crops provide the highest yield of grain in crop rotations. The yield of grain per hectare of arable land was 2,17 and 1,71 t with an average productivity of all studied crop rotations of 1,60 t. When forming the structure of crops for arid regions, it is necessary to use crops of different economic and biological types. When forming the structure of crops for arid regions, it is necessary to include crops of different economic and biological types: winter, early and late spring. The inclusion of drought-resistant late crops that can compensate for crop losses of other crops ensures stabilization of output. A necessary condition for ensuring the stability of productivity due to the low value of the hydrothermal coefficient in arid conditions is the inclusion of the pair winter wheat link. It is also advisable to include corn and grain sorghum in the structure of sown areas, since these crops provide the highest grain yield in crop rotations.
\end{abstract}

Keywords: productivity, yield, crop rotation, hydrothermal coefficient, corn, sorghum

Саратовская область является зоной рискованного земледелия, где засушливые или сухие годы чередуются со влажными. Практически каждый год отмечается недостаточная влагообеспеченность, половина лет являются острозасушливыми [1]. Подобная тенденция в изменении основных агроклиматических характеристик отрицательно проявилась и в дальнейшем может сказаться на снижении продуктивности 
не только основных зерновых, зернофуражных и кормовых культур, но и агроценозов в целом [2].

C потеплением климата связан значительный рост площади посева озимой пшеницы. Среднегодовая температура воздуха увеличивается на $0,36^{\circ}$ за 10 лет, а температура зимнего сезона - на $0,6^{\circ}$ за 10 лет, т.е. темпы роста температуры воздуха в зимний период значительно выше, чем в среднем за год. Сумма средних по области годовых осадков за последние 30 лет увеличилась на 24 мм, а за май - июль уменьшилась на 3 мм. Для озимых культур улучшились условия зимовки. В то же время ухудшились условия для ранних яровых культур вследствие повышения засушливости климата в мае - июле. Если амплитуда колебаний урожайности озимой пшеницы составляет $42 \%$, то яровой $-68 \%$.

Установлено, что фитосанитарная и фитомелиоративная роль севооборотов с зерновыми колосовыми культурами, после которых в почву поступают растительные остатки с широким отношением углерода и азота и с содержанием до $60 \%$ трудногидролизуемой фракции углеродсодержащих веществ, снижается. В зернопаровых севооборотах по сравнению с зернопаропропашными микробная масса с 0,760 мг/г почвы уменьшается до 0,279, в 2,5-3,0 раза увеличивается численность в почве конидий фитопатогенного гриба Helmin-thosporiumsativum, вызывающего заболевание растений корневыми гнилями, снижающими их продуктивность [3]. Вредоносными организмами уничтожается до 30-40 \% продукции растениеводства, несмотря на рост количества и ассортимента применяемых пестицидов.

Рассматривая всю проблему совершенствования структуры севооборотов и устойчивости производства зерна в целом, необходимо четко представлять, что в первую очередь в рыночных условиях спрос и цены на продукцию определяют набор возделываемых культур и, соответственно, структуру посевных площадей. С большей уверенностью при нынешнем соотношении цен можно ожидать снижения площадей посевов яровой пшеницы и увеличения доли озимой пшеницы в структуре посевов и закупок зерна. Снижение уровня интенсификации земледелия, в свою очередь, делает невозможным ведение севооборотов с длинной ротацией, требующих внесения минеральных удобрений и применения гербицидов. Использование в агроценозах только озимых и ранних яровых культур ограничива- ет использование осадков второй половины лета [4]. Таким образом, основной принцип построения севооборотов в засушливой черноземной степи Поволжья заключается в оптимальном сочетании в структуре посевов культур различных биологических групп - озимых по черному пару, ранних и поздних яровых, способных использовать осадки всего сельскохозяйственного года и компенсировать потери одних культур урожаями других, менее пострадавших или не пострадавших от засухи [5]. Введение в севообороты культур этих биологических групп позволяет улучшить степень использования влаги, поступающей в почву в течение вегетационного периода [6].

При постоянном дефиците влаги в большинстве микрозон Саратовской области трудно найти более засухоустойчивую, жаростойкую и солевыносливую культуру универсального назначения, чем сорго, которая могла бы обеспечить стабильность производства и разнообразие кормов [7].

Цель исследований: определить эффективность включения кукурузы и зернового сорго в севообороты с короткой ротацией.

\section{Материалы и методы исследования}

Исследования проводились в 20112019 гг. на опытном поле ФГБНУ РосНИИСК «Россорго». Посев озимых и ранних яровых культур проводился в оптимальные сроки сплошным рядовым способом с использованием сеялок С3-3,6; посев сорго зернового и кукурузы - широкорядным способом с междурядьями $70 \mathrm{~cm}$ сеялкой СО-4,2.

Экспериментальная работа осуществлялась в соответствии с методическими рекомендациями [8-10]. Учет урожайности проводился сплошным методом с учетной делянки. Повторность в опытах трехкратная. Размещение делянок систематическое. Общая площадь опыта - 2,66 га, учетная площадь - $100 \mathrm{~m}^{2}$.

Статистическая обработка экспериментальных данных проводилась методом двухфакторного дисперсионного анализа с помощью программы «AGROS 2.09».

B изучении находились зернопаропропашные севообороты:

1) пар, озимая пшеница, яровая пшеница;

2) пар, озимая пшеница, яровой ячмень;

3) пар, озимая пшеница, зерновое сорго;

4) пар, озимая пшеница, кукуруза.

В качестве материала для исследований использовались следующие сорта сельскохозяйственных культур: озимая пшеница 
(Левобережная 3); яровая мягкая пшеница (Саратовская 68); сорго зерновое (Перспективный 1); яровой ячмень (Нутанс 553); кукуруза (Радуга).

Почва опытного поля - слабо выщелоченный южный чернозем, среднесуглинистого гранулометрического состава. В пахотном слое содержание гумуса составляет $3,5-4,2 \%$, гидролизуемого азота - 10-15 мг, доступного фосфора - 2,4-12,0 мг, обменного калия - 21-32 мг, кальция - до 8 мг на 100 г почвы, определение нитратов проводилось ионометрическим методом: ГОСТ 26951-86, определение подвижных соединений фосфора и калия - по методу Мачигина: ГОСТ26205-91.

Годы исследований различались по метеорологическим условиям. Размах варьирования суммы выпавших осадков составил 95-415 мм, а суммы положительных температур - от $2945^{\circ} \mathrm{C}$ до $359^{\circ} \mathrm{C}$. Гидротермический коэффициент (ГТК) за период апрель - сентябрь варьировал в интервале 0,32-1,27. Благоприятным для роста и развития сельскохозяйственных культур являлся только 2017 г., ГТК за апрель - сентябрь составил 1,21. Исследования проводились в различные по погодным условиям годы, что позволило всесторонне оценить продуктивность изучаемых культур и севооборотов (рис. 1).

\section{Результаты исследования и их обсуждение}

Формирование урожая в засушливых условиях обусловлено различной спо- собностью растений противостоять неблагоприятным физическим, химическим и биологическим стрессам и использовать почвенно-климатические условия. В ходе исследований в трехпольном севообороте отмечено сильное варьирование по показателям урожайности зерна сельскохозяйственных культур.

Урожайность озимой пшеницы в годы исследований на 0,48-2,84 т/га выше, чем яровых зерновых культур. Интервал варьирования показателя по ротациям составил от 1,26 до 4,06 т/га. Средняя урожайность по ротациям составляет 2,62 т/га. Наблюдается увеличение урожайности озимой пшеницы, на что повлияли в основном погодные условия, так как в паровом поле агротехника существенно не изменялась, а также не было изменений при возделывании самой культуры.

Урожайность яровой мягкой пшеницы в среднем за период исследований составляла 1,19 т/га, в первую ротацию - 0,96 т/га, во вторую - 1,39 т/га, в третью - 1,22 т/га. Урожайность ярового ячменя увеличивается от первой ротации $(0,78$ т/га) к третьей $(1,41$ т/га). В среднем за годы исследований урожайность составляет 1,11 т/га.

Максимальная средняя урожайность зерна получена у кукурузы (3,89 т/га) и зернового сорго (2,53 т/га). У кукурузы низкий показатель получен во вторую ротацию $(3,17$ т/га), высокий - в первую $(4,35$ т/га). Урожайность зернового сорго увеличивалась от ротации к ротации, от 1,70 до 3,12 т/га.

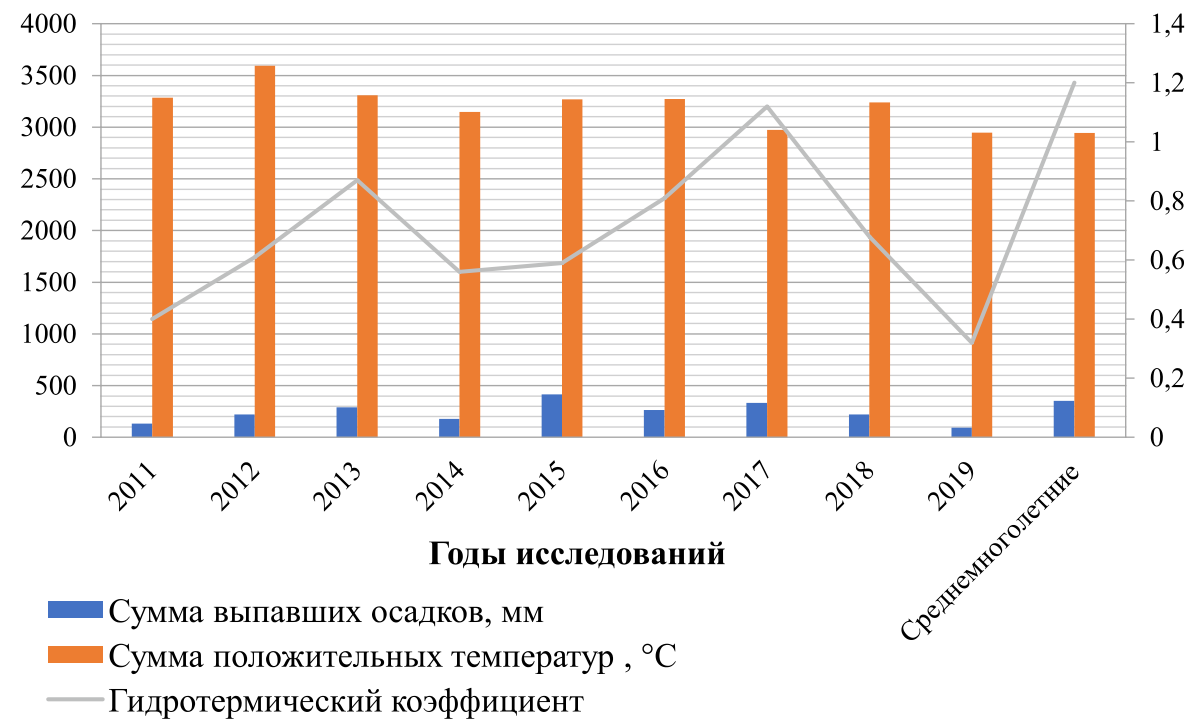

Рис. 1. Погоднье условия в годы исследований, 2011-2019 г2. 
К третьей ротации урожайность культур севооборота возросла на 0,26-2,8 т/га, что обусловлено накопительным влиянием чередования культур на формирование урожая (табл. 1).

В двухфакторном опыте в ходе анализа источников варьирования установлено, что доля культуры в общей изменчивости по фактору А составляет $28,5 \%$. Вклад в общую изменчивость фактора В - 41,6\%, совместного влияния факторов не выявлено.

Содержание белка в зерне - один из важнейших показателей качества. Дан- ный показатель необходимо контролировать для определения питательной ценности зерна. В экспериментальных севооборотах средний выход протеина за три ротации составил: озимая пшеница - 0,34 т/га, яровая пшеница - 0,18 т/га, ячмень - 0,14 т/га, кукуруза - 0,53 т/га, зерновое сорго - 0,22 т/га. Выход протеина с единицы площади у озимой пшеницы по ротациям варьировал в интервале $0,19-0,47$ т/га, яровой пшеницы - 0,11-0,23 т/га, ячменя - 0,08-0,22 т/га, кукурузы - 0,46-0,61 т/га, сорго - 0,190,40 т/га (табл. 2).

Урожайность зерна сельскохозяйственных культур

Таблица 1 в трехпольных севооборотах (т/га), 2011-2019 гг.

\begin{tabular}{|c|c|c|c|c|c|}
\hline \multirow{2}{*}{ 泀 } & \multirow[b]{2}{*}{ Культура (фактор А) } & \multicolumn{3}{|c|}{ Фактор В } & \multirow[b]{2}{*}{ Среднее } \\
\hline & & 1-я ротация & 2-я ротация & 3-я ротация & \\
\hline 1 & Чистый пар & - & - & - & - \\
\hline 2 & Озимая пшеница & 1,26 & 2,53 & 4,06 & 2,62 \\
\hline \multirow{4}{*}{3} & Яровая пшеница & 0,96 & 1,39 & 1,22 & 1,19 \\
\hline & Ячмень & 0,78 & 1,14 & 1,41 & 1,11 \\
\hline & Кукуруза & 4,35 & 3,17 & 4,16 & 3,89 \\
\hline & Сорго зерновое & 1,70 & 2,77 & 3,12 & 2,53 \\
\hline \multicolumn{5}{|l|}{$\mathrm{F}_{0,05}(\mathrm{~A})$} & $20,336^{*}$ \\
\hline $\mathrm{F}_{0,05}(\mathrm{~B})$ & & 1,78 & 2,20 & 2,81 & $7,004^{*}$ \\
\hline \multicolumn{5}{|l|}{$\mathrm{F}_{0,05}(\mathrm{AB})$} & 2,246 \\
\hline \multicolumn{5}{|l|}{$\mathrm{HCP}(\mathrm{A})$} & 0,732 \\
\hline \multicolumn{5}{|l|}{$\mathrm{HCP}(\mathrm{B})$} & 0,567 \\
\hline \multicolumn{5}{|l|}{$\mathrm{HCP}(\mathrm{AB})$} & - \\
\hline
\end{tabular}

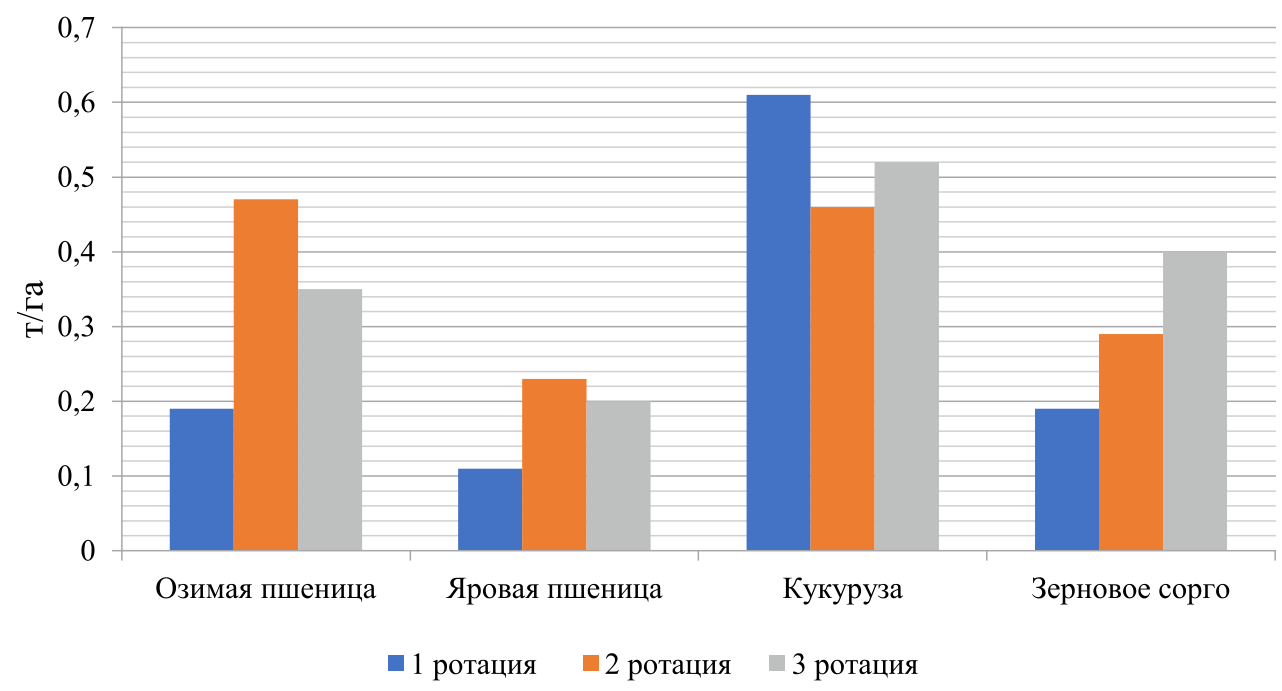

Рис. 2. Выход протеина с единиць площчади по культурам экспериментальных севооборотов, 2011-2019 г2. 
Продуктивность трехпольных севооборотов, 2011-2019 гг.

\begin{tabular}{|c|c|c|c|c|}
\hline \multirow{3}{*}{ Чередование культур в севообороте (фактор А) } & \multicolumn{4}{|c|}{ Выход зерна с севооборотной площади, т/га } \\
\hline & \multicolumn{3}{|c|}{ Фактор В } & \multirow{2}{*}{ Средний } \\
\hline & 1-я ротация & 2-я ротация & 3-я ротация & \\
\hline Пар, озимая пшеница, яровая пшеница & 0,74 & 1,31 & 1,76 & 1,27 \\
\hline Пар, озимая пшеница, ячмень & 0,68 & 1,27 & 1,82 & 1,25 \\
\hline Пар, озимая пшеница, кукуруза & 1,87 & 1,90 & 2,74 & 2,17 \\
\hline Пар, озимая пшеница, сорго зерновое & 0,99 & 1,76 & 2,39 & 1,71 \\
\hline \multicolumn{4}{|l|}{$\mathrm{F}_{0,05}(\mathrm{~A})$} & $7,844^{*}$ \\
\hline $\mathrm{F}_{0,05}(\mathrm{~B})$ & 1,07 & 1,56 & 2,18 & $17,139 *$ \\
\hline \multicolumn{4}{|l|}{$\mathrm{F}_{0.05}(\mathrm{AB})$} & 0,421 \\
\hline \multicolumn{4}{|l|}{$\mathrm{HCP}(\mathrm{A})$} & 0,454 \\
\hline \multicolumn{4}{|l|}{$\mathrm{HCP}(\mathrm{B})$} & 0,393 \\
\hline \multicolumn{4}{|l|}{$\mathrm{HCP}(\mathrm{AB})$} & - \\
\hline
\end{tabular}

Оценка продуктивности севооборотов проводилась как в среднем за 2011-2019 гг., так и отдельно по ротациям. Максимальная продуктивность достигается при равном сочетании в структуре посевов черного пара, озимой пшеницы и кукурузы. Выход зерна в таких севооборотах составил 2,17 т, в том числе в первую ротацию - 1,87 т; во вторую1,90 т и в третью $-2,74$ т зерна с 1 гектара пашни. Несколько меньший выход зерна отмечен при чередовании полей: пар, озимая пшеница, зерновое сорго - 1,71 т при средней продуктивности всех изучаемых севооборотов 1,60 т. По ротациям продуктивность варьировала от 0,99 до 2,39 т/га. Замена поздних культур полем яровой пшеницы снижает выход зерна до 1,27 т, при замене яровым ячменем - до 1,25 т (табл. 2).

Во всех вариантах опыта выход зерна с гектара увеличивался по ротациям. Продуктивность севооборотов с яровой пшеницей изменилась от 0,74 т до 1,76 т, с яровым ячменем - от 0,68 т до 1,82 т, с кукурузой - от 1,87 т до 2,74 т, с зерновым сорго от 0,99 т до 2,39 т.

Доля фактора А в общей изменчивости по показателю «продуктивность севооборотов» составляет $57,1 \%$, фактора $\mathrm{B}-41,56 \%$, совместного влияния факторов не определено.

\section{Заключение}

В ходе проведенных исследований выявлено, что наибольшей урожайностью зерна характеризуются кукуруза, озимая пшеница и сорго. При этом озимая пшеница максимально использует весенние запасы влаги и питательных веществ в сравнении с другими культурами севооборотов. Включение звена пар - озимая пшеница является необходимым условием для обеспечения устойчивой продуктивности в связи с низким значением гидротермического коэффициента в засушливых условиях. В условиях Нижнего Поволжья целесообразно включать в структуру посевных площадей кукурузу и зерновое сорго, так как эти культуры обеспечивают наибольший выход зерна в севооборотах.

\section{Список литературы / References}

1. Пронько В.В., Левицкая Н.Г. Использование зерновыми культурами биоклиматического потенциала сухой степи Заволжья // Вестник СГАУ им. Н.И. Вавилова. 2008. № 1. C. 18-21.

Pronko V.V., Levitskaya N.G. Use of the bioclimatic potential of the dry steppe of the Volga region by grain crops // Vestnik SGAU im. N.I. Vavilova. 2008. No. 1. P. 18-21 (in Russian).

2. Курдюков Ю.Ф., Левицкая Н.Г., Васильева М.Ю. Повышение продуктивности и устойчивости агроэкосистем в степной зоне Поволжья // Аграрная наука. 2014. № 3. C. $10-11$.

Kurdyukov Y.F., Levitskaya N.G., Vasiliev M.Yu. Increasing the productivity and sustainability of agro-ecosystems in the steppe zone of Volga region// Agrarnaya nauka. 2014. No. 3. P. $10-11$ (in Russian).

3. Круглов Ю.В., Курдюков Ю.Ф., Шубититзе Г.В. Микробиологическая активность чернозема южного в зависимости от агротехнических приемов в засушливой степи Нижнего Поволжья // Аграрный научный журнал. 2018. № 1. C. $20-23$.

Kruglov Y.V., Kurdyukov Y.F., Shubitidze G.V. Microbiological activity of southern chernozem dependent on agrotechnic measures in the dry steppe zone of the Lower Volga region // Agrarnyy nauchnyy zhurnal. 2018. No. 1. P. 20-23 (in Russian).

4. Курдюков Ю.Ф., Лощинина Л.П., Фирсов А.И., Шубитидзе Г.В., Куликова Г.А., Третьяков М.В., Щукин С.А., Михайлин Н.В., Бауров А.В., Лебедев В.Б., Пискунова Г.В., Левицкая Н.Г., Зайцев А.Н. Теоретические основы построения полевых севооборотов и оптимизация структуры посев- 
ных площадей в Правобережье Саратовской области: методические рекомендации. Саратов, 2010. С. 45.

Kurdyukov Y.F., Loshchinina L.P., Firsov A.I. Shubitidze G.V., Kulikova G.A., Tretyakov M.V., Shchukin S.A. Mikhailin N.V., Baurov A.V., Lebedev V.B., Piskunova G.V., Levitskaya N.G., Zaitsev A.N. Theoretical basis for constructing field crop rotations and optimizing the structure of sown areas in the right Bank of the Saratov region. Methodical recommendation. Saratov, 2010. P. 45 (in Russian).

5. Плаксина В.С., Ерохина А.В. Эффективность выращивания зернового сорго в севооборотах с различной ротацией // Вестник Вятской ГСХА 2019. № 2. [Электронный ресурc]. URL: http://vvgsha.info/wpcontent/uploads/journal/2019/2/N2 2019 plaksina erokhina effectivnVyrashZernovogoSorgo.pdf (дата обращения: 20.11.2020).

Plaksina V.S., Erokhina A.V. The efficiency of growing grain sorghum in crop rotations with different rotation Vestnik Vyatskoy GSKHA. 2019. No. 2. [Electronic resource]. URL: http://vvgsha.info/wpcontent/uploads/journal/2019/2 N2 2019 plaksina erokhina effectivnVyrashZernovogoSorgo. pdf (date of access: $20.11 .20 \overline{20}$ ) (in Russian).

6. Плаксина В.С. Водопотребление сельскохозяйственных культур в полевых севооборотах // Вавиловские чтения-2019: материалы международной научно-практической конференции посвященной 132-ой годовщине со дня рождения Н.И. Вавилова (г. Саратов, 25-26.11.2019 г.). Саратов: Изд-во «Амрит», 2019. С. 149-151.
Plaksina V.S. Water Consumption of agricultural crops in field crop rotations // Vavilovskiye chteniya-2019: materialy mezhdunarodnoy nauchno-prakticheskoy konferentsii posvyashchennoy 132-oy godovshchine so dnya rozhdeniya N.I. Vavilova (g. Saratov, 25-26.11.2019 g.) Saratov: Izd-vo «Amrit», 2019. P. 149-151 (in Russian).

7. Кибальник О.П., Ефремова И.Г., Семин Д.С., Горбунов В.С., Каменева О.Б., Старчак В.И., Куколева С.С. Оценка качества зерна и биомассы сорго с целью использования в кормопроизводстве // Зерновое хозяйство России. 2019. № 4 C. $3-7$.

Kibalnik O.P., Efremova I.G., Semin D.S., Gorbunov V.S., Kameneva O.B., Starchak V.I., Kukoleva S.S. Evaluation of the quality of grain and sorghum biomass for use in feed production // Zernovoye khozyaystvo Rossii. 2019. No. 4. P. 3-7 (in Russian).

8. Доспехов Б.А. Методика полевого опыта (с основами статистической обработки результатов исследований). М.: Книга по Требованию, 2012. 352 с

Dospehov B.A. Technique of field experiment (with bases of statistical processing of results of researches). M.: Kniga po Trebovaniyu, 2012. 352 p. (in Russian).

9. Методика государственного сортоиспытания сельскохозяйственных культур. М., 2019. 329 с.

Methods of state variety testing of agricultural crops. M., 2019. 329 p. (in Russian).

10. ГОСТ 10846-91 Зерно и продукты его переработки. Метод определения белка. М.: Изд-во стандартов, 1991. 38 с. 